\title{
Endovascular Neurosurgery in the Northern Macro- region of Rio Grande do Sul: Part I
}

\section{Neurocirurgia endovascular na macrorregião norte do Rio Grande do Sul: parte I}

\author{
José Ricardo Vanzin ${ }^{1}$ Nério Dutra Azambuja J ${ }^{1} \quad$ Leonardo Frighetto $^{1} \quad$ Alan Christmann Frohlich ${ }^{1}$ \\ Daniel Lima Varela ${ }^{1}$ Paulo Mesquita Filho ${ }^{1}$ Alex Roman $^{1}$ Luciano Bambini Manzato ${ }^{1}$ \\ ${ }^{1}$ Interventional Neuroradiology Service of Passo Fundo, Passo Fundo, \\ RS, Brazil \\ Arq Bras Neurocir 2018;37:167-173. \\ Address for correspondence José Ricardo Vanzin, MD, Serviço de \\ Neurorradiologia Intervencionista de Passo Fundo, Rua Teixeira \\ Soares, 640, Passo Fundo, RS, Brazil. CEP: 99010-080 \\ (e-mail:vanzin@neurosnn.com.br).
}

\begin{abstract}
Keywords

- arteriography

- interventional radiology

- neuroangiography

- endovascular technique
\end{abstract}

Resumo
Introduction The city of Passo Fundo, in the north of the Rio Grande do Sul state, has been standing out in the health care field for many years. The state has become a reference in endovascular interventional neuroradiology. We will cover 10 years of experience in this area and divide our observations in 3 parts: cerebral angiograms (part I), carotid angioplasties (part II) and intracranial aneurysms (part III). The goal of part $I$ is to statistically assess the cerebral angiograms, their indications, risks and complications, as well as to do a technical review.

Materials and Methods A retrospective study from 2005 to 2015 with a total of 5,567 interventional neuroradiology procedures performed. A total of 4,114 angiograms, 639 embolizations of intracranial aneurysms, 414 carotid angioplasties, 143 embolizations of cerebral arteriovenous malformations, 32 embolizations of dural arteriovenous fistulas, 102 cerebral vasospasm treatments, 21 treatments of epistaxis, 36 embolizations of craniocervical tumor, 25 thrombolysis of ischemic stroke, 18 vertebroplasties and 13 embolizations of arteriovenous malformations of the face.

Results A total of 4,084 procedures performed, 21,811 vessels studied, average vase $7.62 / 2.82$ vessel and patient/procedure. Of these, 2,536 were diagnostic procedures and 1,548 angiographic controls. Of the total, 1,188 patients received only an angiogram, $27.14 \%$ of which were therapeutic procedures. We obtained a total of $3.89 \%$ complications: $2.33 \%$ reflection vasovagal, $0.56 \%$ allergic skin reaction, anaphylactic shock $0.07 \%, 0.27 \%$ femoral hematoma, $0.26 \%$ transient neurological deficit, $0.12 \%$ permanent neurological deficit and no case of death.

Conclusion Cerebral angiography in adults, children and infants is a safe procedure with low risk of permanent neurological complications.

Introdução A cidade de Passo Fundo, localizada no norte do RS, se destaca na área de saúde há muitos anos. $O$ estado se tornou referência em neurocirurgia endovascular. Abordaremos 10 anos de experiência nesta área e dividiremos nossas observações em received

March 1, 2016

accepted

March 10, 2016

published online

October 25, 2016
DOI https://doi.org/

10.1055/s-0036-1584685. ISSN 0103-5355.
Copyright $(2018$ by Thieme Revinter

Publicações Ltda, Rio de Janeiro, Brazil
License terms

(c) (i) $\ominus$ (\$) 


\author{
Palavras-chave \\ - arteriografia \\ - radiologia \\ intervencionista \\ - neuroangiografia \\ - técnica \\ endovascular
}

3 partes: angiografias cerebrais (parte I), angioplastias de carótida (parte II) e aneurismas intracranianos (parte III). O objetivo da parte I é avaliar estatisticamente as angiografias cerebrais, suas indicações, riscos e complicações, assim como realizar uma revisão da técnica.

Materiais e Métodos Estudo retrospectivo de 2005 a 2015, com um total de 5.567 procedimentos neurorradiológicos realizados. São 4.114 angiografias, 639 embolizações de aneurismas intracranianos, 414 angioplastias de carótida, 143 embolizações de malformações arteriovenosas (MAVs) cerebrais, 32 embolizações de fístulas arteriovenosas durais, 102 tratamentos de vasoespasmo cerebral, 21 tratamentos de epistaxe, 36 embolizações de tumores craniocervicais, 25 trombólises de acidente vascular cerebral (AVC) isquêmico, 18 vertebroplastias e 13 embolizações de malformações arteriovenosas de face.

Resultados Um total de 4.084 procedimentos realizados, 21.811 vasos estudados, média de 7,62 vasos por paciente e 2,82 vasos por procedimento. Destes, foram 2.536 procedimentos diagnósticos e 1.548 controles angiográficos. Do total, 1.188 pacientes realizaram apenas uma angiografia, e destes, $27,14 \%$ foram procedimentos terapêuticos. Obtivemos um total de complicações de 3,89\%: $2,33 \%$, reflexo vasovagal; $0,56 \%$, reação alérgica cutânea; $0,07 \%$, choque anafilático; $0,27 \%$, hematoma femoral; $0,26 \%$, déficit neurológico transitório; e $0,12 \%$, déficit neurológico definitivo. Não houve caso de óbito.

Conclusão A angiografia cerebral em adultos, crianças e lactentes é um procedimento seguro, com baixo risco de complicações neurológicas permanentes.

\section{Introduction}

Brazilian endovascular neurosurgery has evolved rapidly in the adjuvant treatment of encephalic vascular pathologies in the past 30 years. Initially used in cases too complex for conventional vascular microsurgery, it has today a wide application in the area of vascular neurosurgery. With the improvement of the technique, the hemodynamic rooms, and the devices for the treatment of vascular diseases, the technique was consolidated all over Brazil. New centers were created, and more professionals were trained both in Brazil and abroad. Thus, endovascular neurosurgery was reaching new areas previously deprived of access to this technology. Interventional neuroradiology has been a challenge for midsize medical centers in the interior of the country, where multidisciplinary teams do not always have a full team of specialists and appropriate equipment. The city of Passo Fundo, located in the north of the state of Rio Grande do Sul (RS), has been standing out in the health services field for several years and, in September 2015, it won the Isto $E$ magazine prize for best mid-sized city for health care, among 5,565 competing municipalities. We will analyze the endovascular neurosurgical activity of the past 10 years at the Neurology and Neurosurgery Service (Serviço de Neurologia e Neurocirurgia [SNN, IN THE Portuguese acronym]) of Passo Fundo. This approach was divided into stages; the most relevant procedures were included in the analysis and divided into three parts: cerebral angiograms (part I), followed by percutaneous carotid angioplasty with stent implantation (part II), and, intracranial aneurysms (part III). Cerebral angiography is used for both diagnosis and intervention. With advances in nonin- vasive vascular imaging tests such as Doppler, CT angiography and MRI angiography, angiography has been reserved for situations in which studies may be inconclusive, or when two studies are contradictory. However, it still remains as the gold standard for the detection of cerebral aneurysms in non-traumatic subarachnoid hemorrhages $(\mathrm{SAHs}){ }^{1-5}$ The objective of this study is to statistically evaluate cerebral angiograms, their indications, risks and complications, as well as a review of the technique.

\section{Materials and Methods}

Hospital medical records were retrospectively analyzed and cross-referenced with prospective collections. The retrospective search was performed by medical students-participants of the neurology and neurosurgery leagues of the São Vicente de Paulo hospitals and Hospital da Cidade-coordinated by the SNN. The prospective database was fed daily by endovascular physicians-neurosurgeons José Ricardo Vanzin and Luciano Bambini Manzato through an Excel table (Microsoft Corp., Remond, WA, US) completed at the end of each procedure. The neurovascular endovascular procedures were performed in three hospitals: Hospital São Vicente de Paulo (HSVP, in the Portuguese acronym), Hospital Pronto Clínica (HPC, in the Portuguese acronym) and Hospital Cidade (HC, in the Portuguese acronym), all located in Passo Fundo. Initially, the procedures were performed with Philips Integris BV5000 (Healthcare, DA Best, The Netherlands) at HSVP from 2005 to 2008; Philips BV Bracelet at HPC, from 2005 to 2012; and Shimadzu Opescope Actin (Shimadzu 
Medical Systems, Kyoto, Japan) at HC from 2006 to 2010. We currently work with Shimadzu Trinias F12 at HPC, GE Innova 3000 and 4000 (GE, Boston, MA, US) at HSVP, and Shimadzu Bransist SAFIRE at HC. Hospital da Cidade and HSVP work with two and three hemodynamic machines, respectively. From July 1, 2005 to December 31, 2015, we studied 2,861 patients between the ages of 2 and 89 years old, with a mean of 52.8 years. The patients were submitted to 5,575 interventional neuroradiological procedures. Of these, $37.9 \%$ underwent 2 or more angiographic procedures. Of the 5,557 procedures in hemodynamics, 4,114 were angiograms, all using the Seldinger technique. In all therapeutic procedures, the initial intention was to perform angiographies of the four cerebral vessels, even if they had CT angiography or MR angiography previously, except for 18 cases of vertebroplasties. The endovascular procedure included: study of the right and left common cervical carotid arteries, right and left intracranial internal carotids, right and left vertebral arteries, aortic arch, and in some cases selective study of the external carotid artery. The origin of the patients was $54 \%$ of the neurological and neurosurgical staff ( 8 professionals in the service), the emergency rooms of the 3 hospitals (32\%) and the referrals of neurologists and neurosurgeons in the northern region of the state of Rio Grande do Sul (14\%). Patients from the Brazilian Unified Health System (SUS, in the Portuguese acronym) were accepted only when they came from the northern macro-region of RS, which comprises the 6th, 11th, 15th and 19th health coordinating centers ( - Fig. $\mathbf{1}$ ).

The main pathologies that required an angiographic study were SAH (39\%), cerebral ischemia due to atheromatous disease (26\%), and intraparenchymal hematoma (17\%). In this period, 1,443 therapeutic procedures were performed, 639 cerebral aneurysm embolizations, 414 percutaneous angioplasties with stent implantation, 143 embolizations of cerebral and spinal arteriovenous malformations, 32 dural fistulas, 102 angioplasties for vasospasm, 21 epistaxis treatments, 36 pre-operative embolizations of craniocervical tumors, 25 intra-arterial chemical and/or mechanical thrombolysis, 18 vertebroplasties and 13 vascular malformations of the face. All patients were monitored with venous access, cardiac monitor, and pulse oximetry. Non-ionic iodinated contrast and manual injections were used, except for the aortic arch, in which an infusion pump was used with $40 \mathrm{~mL}$ of iodinated contrast, at a rate of $20 \mathrm{~mL} / \mathrm{s}$ with 600 pounds per square inch (PSI). Removal of the femoral sheath was performed by the neuroradiologist, resident physician of neurosurgery, or standard nurse of the sector, with the patient remaining at rest and under observation for 6 hours in the hemodynamics sector. The patients were released after receiving instructions to rest for another 24 hours and notifying the staff if there were changes. The majority of procedures were performed using $5 \mathrm{~F}$ introducer, $5 \mathrm{~F}$ vertebral diagnostic catheter and 0.035 " hydrophilic guide impregnated with physiological solution. In $19.14 \%$ (785) of the cases, it was necessary to use a Simon II catheter to complete the examination. In 12 children younger than 2 years of age, a modified technique was used by puncturing the femoral artery with an Abbocath cannula (21-gauge needle) 21 attached to the skin with surgical adhesive tape, and the angiographic study using 0.27 " microcatheter and 0.014 " micro-guide. The angiographies for confirmation of brain death were also monitored by anesthesiologists using the Seldinger technique. Complications were recorded by procedure, rather than per individual vessel studied, and classified into transient neurological complication, permanent neurological complication, local, and allergic reactions. Technical changes are routine changes in the angiographic procedure, such as the need for sedation, general anesthesia, puncture at a site other than the femoral artery. Data were crossed and analyzed with the software SPSS Statistics for Windows, version 22.0 (IBM Corp., Armonk, NY, US).

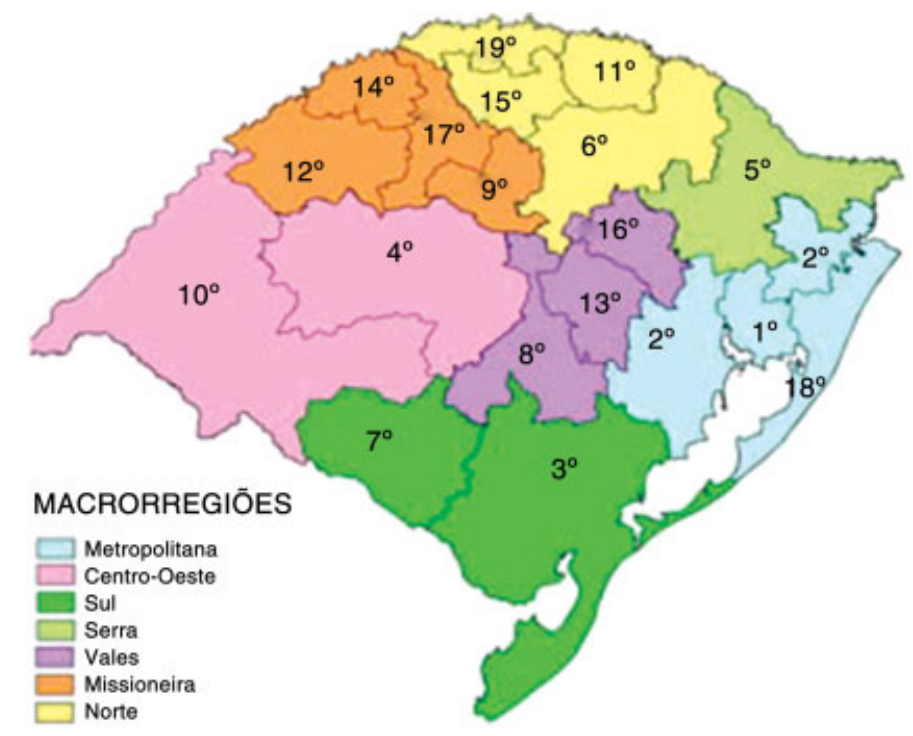

Fonte: ASSTEPLAN/SES-RS

Fig. 1 Distribution of the macro-regions and health coordinates of RS. 
Table 1 Number of vessels studied

\begin{tabular}{|l|l|}
\hline Studied vessel & $\begin{array}{l}\text { Number of studied } \\
\text { vessels }\end{array}$ \\
\hline Common right and left carotid & 5,846 \\
\hline $\begin{array}{l}\text { Right and left internal } \\
\text { carotid artery }\end{array}$ & 7,746 \\
\hline $\begin{array}{l}\text { Right and left external } \\
\text { carotid artery }\end{array}$ & 1,620 \\
\hline Vertebral right and left & 5,326 \\
\hline Medullary-different levels & 836 \\
\hline Other vessels & 437 \\
\hline Total & 21,811 \\
\hline Total/Patient* & 7.62 \\
\hline Total/Procedure & 2.82 \\
\hline
\end{tabular}

Note: *Includes angiographic controls.

\section{Results}

A total of 4,084 procedures were included with a $0.73 \%$ failure rate. All angiograms were performed using the Seldinger technique, with 21,811 vessels studied, mean of 7.62 vessels per patient, and 2.82 vessels per procedure (-Table 1). Of the total, 2,536 were diagnostic procedures and 1,548 angiographic controls of previously treated pathologies, 38 pediatric angiograms ( $<12$ years of age) and 38 angiograms of brain death. In 1,188 patients, only 1 diagnostic angiogram was performed, with no referral for endovascular treatment, that is, $28.9 \%$ of patients who underwent angiographies did not require treatment. All complications were included, both in diagnostic angiograms and in controls. Of the total number of exams, we obtained 160 intercurrences/procedures (3.89\%) divided into types of complications: neurological (transient and permanent), non-neurological (vasovagal reaction and acute renal failure), local (femoral hematoma, carotid/vertebral dissection, broken catheter, acute arterial occlusion, venous thrombosis, arteriovenous fistula), and allergic reactions (skin rash and anaphylactic shock) (-Table 2 ). The transient neurologic complications were: 5 cases with reversible motor focal neurological deficit in less than 1 hour (0.12\%), 4 cases with transient cortical blindness $(0.10 \%)$ and 2 cases of transient global amnesia (0.05\%). The permanent ones were: 1 case of definitive hemiplegia (0.02\%) and 4 cases of neuropathic pain due to puncture $(0.1 \%)$. Of the non-neurological complications, vasovagal reaction $(2.33 \%)$ was the most frequent, followed by reversible acute renal failure (ARF), in 2 cases $(0.05 \%)$. Reaction bradycardia occurred in 96 cases $(2.04 \%)$, with 12 of these progressing to syncope $(0.29 \%)$. Of the total, 62 patients had alteration during the arterial femoral puncture and 34 in the removal of the sheath, requiring the use of venous atropine to recover the heart rate in 16 patients (14.28\%). Patients with syncope required a longer observation period (24 hours). Among the local complications, which totaled 11 cases, 3 were large
Table 2 Complications in cerebral angiography

\begin{tabular}{|c|c|c|}
\hline Complications & Procedures & $\%$ \\
\hline \multicolumn{3}{|l|}{ Neurological } \\
\hline \multicolumn{3}{|l|}{ Transient } \\
\hline Focal motor deficit & 5 & 0.12 \\
\hline Transient cortical blindness & 4 & 0.1 \\
\hline Transient global amnesia & 2 & 0.05 \\
\hline Subtotal & 11 & 0.26 \\
\hline \multicolumn{3}{|l|}{ Permanent } \\
\hline Focal motor deficit & 1 & 0.02 \\
\hline Neuropathic pain & 4 & 0.1 \\
\hline Subtotal & 5 & 0.12 \\
\hline \multicolumn{3}{|l|}{ Non-neurological } \\
\hline \multicolumn{3}{|l|}{ Vasovagal reaction } \\
\hline Syncope & 12 & 0.29 \\
\hline Bradycardia & 84 & 2.04 \\
\hline ARF & 2 & 0.05 \\
\hline Subtotal & 98 & 2.38 \\
\hline \multicolumn{3}{|l|}{ Local } \\
\hline Femoral hematoma & 11 & 0.27 \\
\hline Carotid dissection & 5 & 0.12 \\
\hline Broken catheter & 4 & 0.1 \\
\hline Acute arterial occlusion & 1 & 0.02 \\
\hline Deep vein thrombosis & 1 & 0.02 \\
\hline Arteriovenous fistula & 1 & 0.02 \\
\hline Subtotal & 23 & 0.56 \\
\hline \multicolumn{3}{|l|}{ Allergic reaction } \\
\hline Skin rash & 23 & 0.56 \\
\hline Anaphylactic shock & 3 & 0.07 \\
\hline Subtotal & 26 & 0.63 \\
\hline Total & 160 & 3.89 \\
\hline
\end{tabular}

Abbreviation: ARF, acute renal failure.

femoral hematomas in $0.27 \%$ (promoting pain and discomfort to the patient, without clinical repercussion), 5 cervical dissections $(0.12 \%)$, which in 2 cases required correction with stent implant $(0.05 \%), 4$ cases of rupture of the distal end of the diagnostic catheter $(0.10 \%), 1$ case of acute arterial occlusion of the femoral artery $(0.02 \%), 1$ case of thrombosis $(0.02 \%)$, and 1 case of surgically corrected femoral arteriovenous fistula (0.02\%). Allergic reactions were seen in 23 cases with cutaneous rash $(0.56 \%)$ and 3 cases of anaphylactic shock $(0.07 \%)$ requiring hospitalization (-Table $\mathbf{2}$ ). No cases of death, skin infection at the puncture site, or chronic renal failure related to angiography were identified. Changes in angiographic study strategy occurred in 238 cases (5.78\%), $\sim 1$ in 20 procedures (-Table 3 ). Among them: failure of catheterization $(0.73 \%)$, radial access $(0.85 \%)$, direct puncture of the cervical carotid (0.34\%), direct puncture of 
Table 3 Need for change in brain angiography technique

\begin{tabular}{|l|l|l|}
\hline Technique change & Cases & $\%$ \\
\hline Catheterization failure & 30 & 0.73 \\
\hline Radial access & 35 & 0.85 \\
\hline Carotid direct puncture & 14 & 0.34 \\
\hline Spinal direct puncture & 4 & 0.1 \\
\hline Sedation & 82 & 1.99 \\
\hline General anesthesia & 71 & 1.72 \\
\hline Total & 238 & 5.78 \\
\hline
\end{tabular}

the vertebral artery $(0.1 \%)$, need for sedation (1.99\%) and need for general anesthesia (1.72\%). The catheterization failure occurred in 30 procedures: 18 cases with severe atheromatous disease of the iliac and abdominal vessels, 5 cases of femoral arterial puncture failure due to patient obesity (abdominal apron), 4 cases of cutaneous infection in the inguinal region, and 3 cases due to the presence of bulky bilateral inguinal hernia. All cases of failure were referred to computed tomography (CT) angiography or magnetic resonance (MR) angiography. Direct percutaneous cervical carotid puncture was required in 14 cases, and in 4 , direct puncture of the vertebral artery. All were performed for vascular access in the treatment of intracranial aneurysms in patients with peripheral access difficulty. In 82 cases, mild sedation $-5 \mathrm{mg}$ midazolam and $1 \mathrm{~mL}$ fentanyl-was required during diagnostic angiograms and/or controls, 2 for every 100 exams, due to patient anxiety. Prior scheduling of angiograms with general anesthesia due to psychomotor agitation was required in 71 cases, and most of them (65 cases, $91.55 \%$ ) were patients hospitalized with neurological pathology. Of the four cases of rupture of the distal tip of the diagnostic catheter within the patient, three were removed with a loop, and one, surgically. We did not record the required amount of opening of other materials to complete angiographic studies due to reuse damage. We subjectively observed that the introducers and the hydrophilic guides were the materials with the most exchange. The number of diagnostic exams and procedures remained homogeneous during the 10 years without significant variations. In most cases (74.13\%), there was a predominance of patients treated by the SUS (72.86\%) for the realization of diagnostic and control exams (-Table 4).

\section{Discussion}

Cerebral angiography is used for both diagnosis and treatment of vascular disorders. With advances in noninvasive vascular imaging studies, such as Doppler, CT angiography and MR angiography, angiography has been reserved for situations in which studies may be inconclusive or when two studies are contradictory. ${ }^{1}$ It is indicated for investigation of extracranial diseases (vertebrobasilar insufficiency due to subclavian artery theft syndrome, cervical carotid stenosis, carotid-cavernous fistula, cervical trauma, epistaxis, invasive carotid tumors and tumors embolization) and intracranial diseases (non-traumatic SAH, cerebral aneurysm, arteriovenous malformation, arterial vasospasm, acute stroke, tumor embolization, Wada test). ${ }^{1-5}$ In the literature, complications during angiography vary from 0.4 to $12.2 \%$, in reversible or transient neurologic events, and from 0 to 5,4\% in permanent deficits. ${ }^{6-13} \mathrm{~A}$ meta-analysis of 3 prospective studies by Cloft et al, published in 1999, reports values of 0.9 to $2.3 \%$ of transient neurological complications and 0.1 to $0.5 \%$ of permanent deficits. ${ }^{14}$ Leonardi et al published in 2005 a retrospective cohort study with complication rates of 0.1 and $0.5 \%$ for transient and permanent neurological deficits, respectively. ${ }^{15}$ We observed $0.28 \%$ of transient neurological deficits and $0.12 \%$ of permanent neurological deficits, results similar to those reported in the literature. The most frequent complication was the vasovagal reaction

Table 4 Overall activity over 10 years

\begin{tabular}{|l|l|l|l|l|l|}
\hline Year & T/Year (\%) & A/Year (\%) & Ps/Year (\%) & SUS/Year (\%) & HP/Year (\%) \\
\hline $2005^{*}$ & $208(3.74)$ & $151(3.67)$ & $57(3.97)$ & $140(3.46)$ & $68(4.51)$ \\
\hline 2006 & $482(8.67)$ & $345(8.38)$ & $137(9.55)$ & $343(8.48)$ & $139(9.23)$ \\
\hline 2007 & $530(9.54)$ & $391(9.50)$ & $139(9.69)$ & $398(9.84)$ & $132(8.76)$ \\
\hline 2008 & $525(9.45)$ & $390(9.48)$ & $135(9.41)$ & $411(10.16)$ & $114(7.57)$ \\
\hline 2009 & $526(9.46)$ & $370(8.99)$ & $156(10.87)$ & $363(8.98)$ & $163(10.82)$ \\
\hline 2010 & $636(11.44)$ & $487(11.84)$ & $149(10.38)$ & $481(11.90)$ & $155(10.29)$ \\
\hline 2011 & $562(10.11)$ & $442(10.74)$ & $120(8.36)$ & $431(10.66)$ & $131(8.70)$ \\
\hline 2012 & $386(6.95)$ & $259(6.29)$ & $127(8.85)$ & $284(7.02)$ & $102(6.77)$ \\
\hline 2013 & $489(8.80)$ & $366(8.90)$ & $123(8.57)$ & $341(8.43)$ & $148(9.82)$ \\
\hline 2014 & $545(9.81)$ & $411(9.99)$ & $134(9.34)$ & $390(9.64)$ & $155(10.29)$ \\
\hline 2015 & $668(12.02)$ & $502(12.20)$ & $166(11.01)$ & $461(11.40)$ & $199(13.21)$ \\
\hline Total $^{* *}$ & 5,557 & $4,114^{* * *}(74.13)$ & $1,443(25.86)$ & $4,043(72.86)$ & $1,506(27.14)$ \\
\hline
\end{tabular}

Abbreviations: A, angiography; HP, health plans; Ps, procedures; T, total.

Notes: ${ }^{*}$ Activity from July to December. ${ }^{* *}$ Excluding 18 vertebroplasties from 2008 to 2010. 
(2.34\%), which has been described as a major cardiac event in 3 to $6 \%$ of the cases (syncope), and transient reversible bradycardia in 4 to $7 \%{ }^{16-19}$ Bradycardia occurs during femoral arterial puncture and removal of the femoral sheath, caused by pain and manipulation of the femoral artery. We did not use an allergic preparation for diagnostic or therapeutic angiographic examinations because of the low incidence of anaphylactic shock (0.07\%). Radial access was initially proposed by Piscioni in $1988,{ }^{20}$ who described his preliminary experience in 30 cases. Campeau et al, in 1989, ${ }^{21}$ published a series of 100 cases using radial access for percutaneous coronary angiograms. This route was considered more comfortable for the patient, with better costeffectiveness for the institutions, because it reduces the time of in-hospital observation, makes external compression easy in cases of hemorrhages at the puncture site, and has been preferred by cardiologists instead of the brachial technique, created in 1953. ${ }^{20-22}$ Recently, some interventional cardiologists have used ulnar access as a safe route. ${ }^{22}$ The radial pathway is an option for neuroradiologists, especially in patients with bilateral femoral venous accesses, groin puncture phobias, coagulation disorders, large bruises, or bilateral femoral contusions due to arterial punctures or cutaneous extravasation of venous accesses, severe atheromatous disease of the femoral, iliac and abdominal aorta arteries. ${ }^{23}$ Cases of failure to perform the tests occurred more frequently until 2009 (22 cases, $0.53 \%$ ), since after the introduction of the radial technique there was a reduction of failures ( 8 cases, $0.19 \%)$. Percutaneous cervical carotid puncture for diagnostic studies was abandoned in 1953, after modern angiography was introduced to the scientific world by the Swedish physician Sven Ivar Seldinger. ${ }^{24}$ He described the use of the catheter to insert contrast into the blood vessels. Currently, percutaneous cervical carotid puncture has been used to treat neurological pathologies in selected cases. ${ }^{25-28}$ Percutaneous vertebral artery puncture, initially used for diagnostic exams, ${ }^{29,30}$ has been used as an alternative access for the treatment of cerebral aneurysms of the basilar top, in patients with unfavorable aortic arch, with presence of proximal looping. ${ }^{31,32}$ Children are rarely able to complete an angiography study with local anesthesia due to anxiety, agitation, pain and discomfort at the puncture site, contrast injection, and cerebral dysfunction caused by bleeding or ischemia. The diagnostic study in children and infants is a safe procedure and currently preferred because it is performed with deep sedation instead of general endotracheal anesthesia. ${ }^{33,34}$ Although uncommon in our series, we did not observe any complications. The use of sedation for patients with altered level of consciousness with aneurysmal SAH has been proposed with the use of 1,3-diisopropylphenol (propofol), but dexmedetomidine has been shown to be superior. ${ }^{35}$ For these cases, we always use general anesthesia, with the immediate endovascular treatment plan. For mild sedation in the endovascular neuroendocrine routine, during the diagnostic or control brain angiograms venous use of midazolam and fentanyl is recommended. ${ }^{1,2}$ We observed, in $\sim 2$ cases for every 100 exams the need for sedation with this protocol, often related to the anxiety of patients before the examination. Scheduling of angiograms with general anesthesia due to psychomotor agitation occurs, in most cases, in inpatients and with an approximate frequency of 1.5 for every 100 exams in our series. Of the total number of exams performed in 10 years, $28.9 \%$ of cases of diagnostic angiography did not require treatment-this data in vascular neurology was unknown thus far. Another new finding was the number of treated cases compared with the total number of exams, $25.86 \%$ of all cases were therapeutic endovascular procedures; these data are very similar to those of interventional cardiology, in which $\sim 25$ to $30 \%$ of all cases are treated. ${ }^{36}$ Changes in the angiographic study strategy may occur in $5.78 \%$ of the cases, that is, $\sim 1$ in 20 examinations performed. Most of the diagnostic and therapeutic procedures carried out were SUS (72.86\%), which shows that our activity is essentially public. The lag in hospital and medical fees have been taking place for years. Many hospitals and doctors are not dedicated to providing public services for this reason. SUS does not pay the tools for diagnostic exams such as introducer, guide and diagnostic catheters. Most hospitals work with re-sterilized materials for SUS diagnostic studies to keep their services active, and this increases the risk of complications. For example, in our series, four cases of rupture of the distal tip of the diagnostic catheter occurred during the diagnostic study, which, although infrequent, increases the risk for patients. In countless cases not recorded in our series, there was a need to change the introducer or the hydrophilic guide due to the wear of the reused material, which increased the time of the procedure and psychological wear of the whole team and the patients themselves.

\section{Conclusion}

Cerebral angiography-in adults, children or infants-is a safe procedure, with a low risk of severe allergic reactions or permanent neurological complications. The most frequent complications were vasovagal reflex (bradycardia) and skin rash, without prolongation of observation time or subsequent hospital admission. Changes in the angiographic study strategy can occur in $\sim 6 \%$ of the cases. Risks arising from the reuse of materials should be avoided with changes in the country's public health guidelines.

\section{References}

1 Ahn SH, Prince EA, Dubel GJ. Basic neuroangiography: review of technique and perioperative patient care. Semin Intervent Radiol 2013;30(03):225-233

2 Wallace RC, Curtis A, Lewis CA, et al; American Society of Neuroradiology. American Society of Interventional and Therapeutic Neuroradiology. Society of Cardiovascular and Interventional Radiology. Quality improvement guidelines for adult diagnostic neuroangiography. Cooperative study between the ASNR, ASITN, and the SCVIR. AJNR Am J Neuroradiol 2000;21 (01):146-150

3 Citron SJ, Wallace RC, Lewis CA, et al; Society of Interventional Radiology; American Society of Interventional and Therapeutic Neuroradiology; American Society of Neuroradiology. Quality improvement guidelines for adult diagnostic neuroangiography. 
Cooperative study between ASITN, ASNR, and SIR. J Vasc Interv Radiol 2003;14(9 Pt 2):S257-S262

4 Thiex R, Norbash AM, Frerichs KU. The safety of dedicated-team catheter-based diagnostic cerebral angiography in the era of advanced noninvasive imaging. AJNR Am J Neuroradiol 2010;31 (02):230-234

5 ACR Committee on Drugs and Contrast Media. Version 10.1, 2015. Available from: http://www.acr.org/Quality-Safety/Resources/ /media/37D84428BF1D4E1B9A3A2918DA9E27A3.pdf/

6 Baum S, Stein GN, Kuroda KK. Complications of "no arteriography". Radiology 1966;86(05):835-838

7 Cloft HJ, Kallmes DF, Dion JE. A second look at the second-look angiogram in cases of subarachnoid hemorrhage. Radiology 1997; 205(02):323-324, discussion 324-325

8 Hankey GJ, Warlow CP, Sellar RJ. Cerebral angiographic risk in mild cerebrovascular disease. Stroke 1990;21(02):209-222

9 Hankey GJ, Warlow CP, Molyneux AJ. Complications of cerebral angiography for patients with mild carotid territory ischaemia being considered for carotid endarterectomy. J Neurol Neurosurg Psychiatry 1990;53(07):542-548

10 Heiserman JE, Dean BL, Hodak JA, et al. Neurologic complications of cerebral angiography. AJNR Am J Neuroradiol 1994;15(08): 1401-1407, discussion 1408-1411

11 Kassell NF, Torner JC. Aneurysmal rebleeding: a preliminary report from the Cooperative Aneurysm Study. Neurosurgery 1983;13(05):479-481

12 Kuhn J, Vehlen C, Mennel HD, Mahkorn D, Bewermeyer H. Rupture of an internal carotid artery aneurysm during angiography with leakage of contrast medium via an external ventricular drain. Neuroradiology 2003;45(12):905-907

13 Saitoh H, Hayakawa K, Nishimura K, et al. Rerupture of cerebral aneurysms during angiography. AJNR Am J Neuroradiol 1995;16 (03):539-542

14 Cloft HJ, Joseph GJ, Dion JE. Risk of cerebral angiography in patients with subarachnoid hemorrhage, cerebral aneurysm, and arteriovenous malformation: a meta-analysis. Stroke 1999;30(02):317-320

15 Leonardi M, Cenni P, Simonetti L, Raffi L, Battaglia S. Retrospective study of complications arising during cerebral and spinal diagnostic angiography from 1998 to 2003. Interv Neuroradiol 2005; 11(03):213-221

16 Lightowler JV, Elliott MW. Local anaesthetic infiltration prior to arterial puncture for blood gas analysis: a survey of current practice and a randomised double blind placebo controlled trial. J R Coll Physicians Lond 1997;31(06):645-646

17 Bowden SM, Worrey JA. Assessing patient comfort: local infiltration of lidocaine during femoral sheath removal. Am J Crit Care 1995;4(05):368-369

18 O'Grady E. Removal of a femoral sheath following PTCA in cardiac patients. Prof Nurse 2002;17(11):651-654

19 Juergens CP, Lo S, French JK, Leung DY. Vaso-vagal reactions during femoral arterial sheath removal after percutaneous coronary intervention and impact on cardiac events. Int J Cardiol 2008; 127(02):252-254

20 Piscione F, Villari B, Focaccio A, Cappelli-Bigazzi M, Indolfi C, Chiariello M. [Percutaneous brachial approach in left heart cathe- terization with 5 French catheters. Preliminary experience]. G Ital Cardiol 1988;18(01):17-22

21 Campeau L. Percutaneous radial artery approach for coronary angiography. Cathet Cardiovasc Diagn 1989;16(01):3-7

22 Roghani-Dehkordi F, Hadizadeh M, Hadizadeh F. Percutaneous trans-ulnar artery approach for coronary angiography and angioplasty; A case series study. ARYA Atheroscler 2015;11(05): 305-309

23 Kim JH, Park YS, Chung CG, Park KS, Chung DJ, Kim HJ. Feasibility and utility of transradial cerebral angiography: experience during the learning period. Korean J Radiol 2006;7(01):7-13

24 Seldinger SI. Catheter replacement of the needle in percutaneous arteriography; a new technique. Acta Radiol 1953;39 (05):368-376

25 Halbach VV, Higashida RT, Hieshima GB, Hardin CW. Direct puncture of the proximally occluded internal carotid artery for treatment of carotid cavernous fistulas. AJNR Am J Neuroradiol 1989;10(01):151-154

26 Koenigsberg RA, Aletich V, Camras L, Debrun G, Ausman J. Direct cervical internal carotid access for GDC treatment of an ophthalmic origin carotid aneurysm. Surg Neurol 1999;51(05): 506-508

27 Blanc R, Mounayer C, Piotin M, Sadik JC, Spelle L, Moret J. Hemostatic closure device after carotid puncture for stent and coil placement in an intracranial aneurysm: technical note. AJNR Am J Neuroradiol 2002;23(06):978-981

28 Blanc R, Piotin M, Mounayer C, Spelle L, Moret J. Direct cervical arterial access for intracranial endovascular treatment. Neuroradiology 2006;48(12):925-929

29 Lindgren E. Percutaneous angiography of the vertebral artery. Acta Radiol 1950;33(05):389-404

30 Schechter MM, Gutiérrez-Mahoney CG D. The evolution of vertebral angiography. Neuroradiology 1973;5(03):157-164

31 Weill A, Cognard C, Spelle L, Castaings L, Moret J. Endovascular treatment of basilar tip aneurysms after direct puncture of the vertebral artery. AJNR Am J Neuroradiol 1998;19(08):1554-1556

32 Vanzin JR, Bambini Manzato L, Slaviero F, Strzelecki M, D’agostini Annes R. Direct vertebral artery access for the endovascular treatment of basilar artery aneurysms. Interv Neuroradiol 2012;18(01):29-32

33 Anand KJ, Johnston CC, Oberlander TF, Taddio A, Lehr VT, Walco $\mathrm{GA}$. Analgesia and local anesthesia during invasive procedures in the neonate. Clin Ther 2005;27(06):844-876

34 Peng K, Li J, Ji FH, Li Z. Dexmedetomidine compared with propofol for pediatric sedation during cerebral angiography. J Res Med Sci 2014;19(06):549-554

35 Sriganesh K, Reddy M, Jena S, Mittal M, Umamaheswara Rao GS. A comparative study of dexmedetomidine and propofol as sole sedative agents for patients with aneurysmal subarachnoid hemorrhage undergoing diagnostic cerebral angiography. J Anesth 2015;29(03): 409-415

36 Banning AP, Baumbach A, Blackman D, et al; British Cardiovascular Intervention society. Percutaneous coronary intervention in the UK: recommendations for good practice 2015. Heart 2015; 101(Suppl 3):1-13 